\title{
Stabilization of Johor Peat Soil using Sugarcane Bagasse Ash (SCBA)
}

\author{
Hafiz Arifuddin Nor ${ }^{1}$, Mohd Khaidir Abu Talib ${ }^{1,2^{*}}$, Faizal Pakir ${ }^{1,2}$, Nur Latifah \\ Jumien $^{1}$, Norhaliza Wahab ${ }^{1}$
}

${ }^{1}$ Faculty of Civil Engineering and Built Environment,

Universiti Tun Hussein Onn Malaysia, 86400 Parit Raja, Batu Pahat, Johor, MALAYSIA

${ }^{2}$ Research Centre for Soft Soil,

Universiti Tun Hussein Onn Malaysia, 86400 Parit Raja, Batu Pahat, Johor, MALAYSIA

*Corresponding Author

DOI: https://doi.org/10.30880/jsue.2021.01.01.007

Received 24 August 2021; Accepted 11 October 2021; Available online 16 December 2021

\begin{abstract}
Peat soil have been categorized as a problematic organic soil, because they have a high settlement rate when placed any structure on it. Therefore, the peat soil must first be stabilized using cement before it can be used. However, massive use of cement can lead to environmental pollution. Therefore, this study intends to use sugar cane bagasse ash as a substitute for cement in peat soil stabilization. The mix ratio of $5 \%$ to $20 \%$ was used to find the optimal mix ratio. Various tests were carried out on samples such as basic properties tests, Unconfined Compressive Strength (UCS) and Scanning Electron Microscope (SEM). After all the tests, the 5\% replacement SCBA mix ratio gave the highest unconfined compressive strength if compared to the other mixtures ratio. Therefore, it is selected as the optimum mix ratio. The soil strength achieved by the SCBA 5\% replacement ratio was found to be higher than cement stabilization alone due to the presence of secondary pozzolan reactions. The microstructure result from the SEM test had shown that the 5\% replacement SCBA mix ratio filled in the hollow left by the peat soil. Hence, able to improve its soil structure and thus increasing its strength.
\end{abstract}

Keywords: Peat stabilization, sugarcane bagasse ash, cement replacement, peat strength

\section{Introduction}

In Malaysia, peat soil is estimated to reach up to three million hectares in area. Most can be found mainly in the southern region of the peninsular Malaysia as in Johor and also in Sarawak. Peat soil are less favored by civil engineers around the world especially those who work in geotechnical fields because the features contained in peat soil have made it difficult for construction work. Peat soils have been found to contain low bearing capacity and high settlement rates on any structure constructed above them. Peat also has very low shear strength within a range of 5 to $20 \mathrm{kPa}$. There have been numerous cases reported around the world on road damages due to peat soil instability. Peat soils represent an extreme form in the soft soils category as it could not be inhabited. Any infrastructures constructed on untreated peat soils is most likely to be settled in the long term [1]. Peat usually occurs in aqueous soils that lack oxygen supply which prevents natural microorganisms from decomposing dead plant materials. These conditions occur when dead plants are not decayed and accumulate for years as a peat layer. Peat forms slowly in this way, involving the accumulation of organic matter in water, and take about 10 years for $1 \mathrm{~cm}$ peat to form [2]. In Johor, most peat soil are located on the southern region of Malaysia like Pontian and Batu Pahat [3].

The use of cement and aggregate to make concrete has been used by civil engineers around the world to build many projects. In geotechnical areas, cement is widely used to stabilize unstable soil to provide a solid foundation of construction projects. However, massive use of cement in stabilizing peat soil can lead to some disadvantages of 
various angles and aspects that should be taken into account by civil engineers [4]. The use of cement in small amount will have no significant effect on peat soil stabilization. In contrast to clay and mud, peat has much lower soil particle content and is easier to produce secondary pozzolanic reactions [5]. Cement manufacturing requires a considerable amount of energy because extreme heat is required to produce it. The production of one ton of cement requires about 4.7 million British Thermal Unit (BTU) of energy, generating nearly one ton of carbon dioxide $\left(\mathrm{CO}_{2}\right)$ [6]. This suggests that massive cement applications do not support the development of eco-friendly construction materials. The massive use of cement during the peat stabilization process contributes to the release of $\mathrm{CO}_{2}$ due to concrete production. Cement is responsible for about 5 to $8 \%$ of global carbon oxide emissions and expected to increase by 0.8 to $1.2 \%$ per annum to reach 4.4 billion tonnes production by 2050 [7]. Fig. 1 shows the process of $\mathrm{CO}_{2}$ release during the cement production.

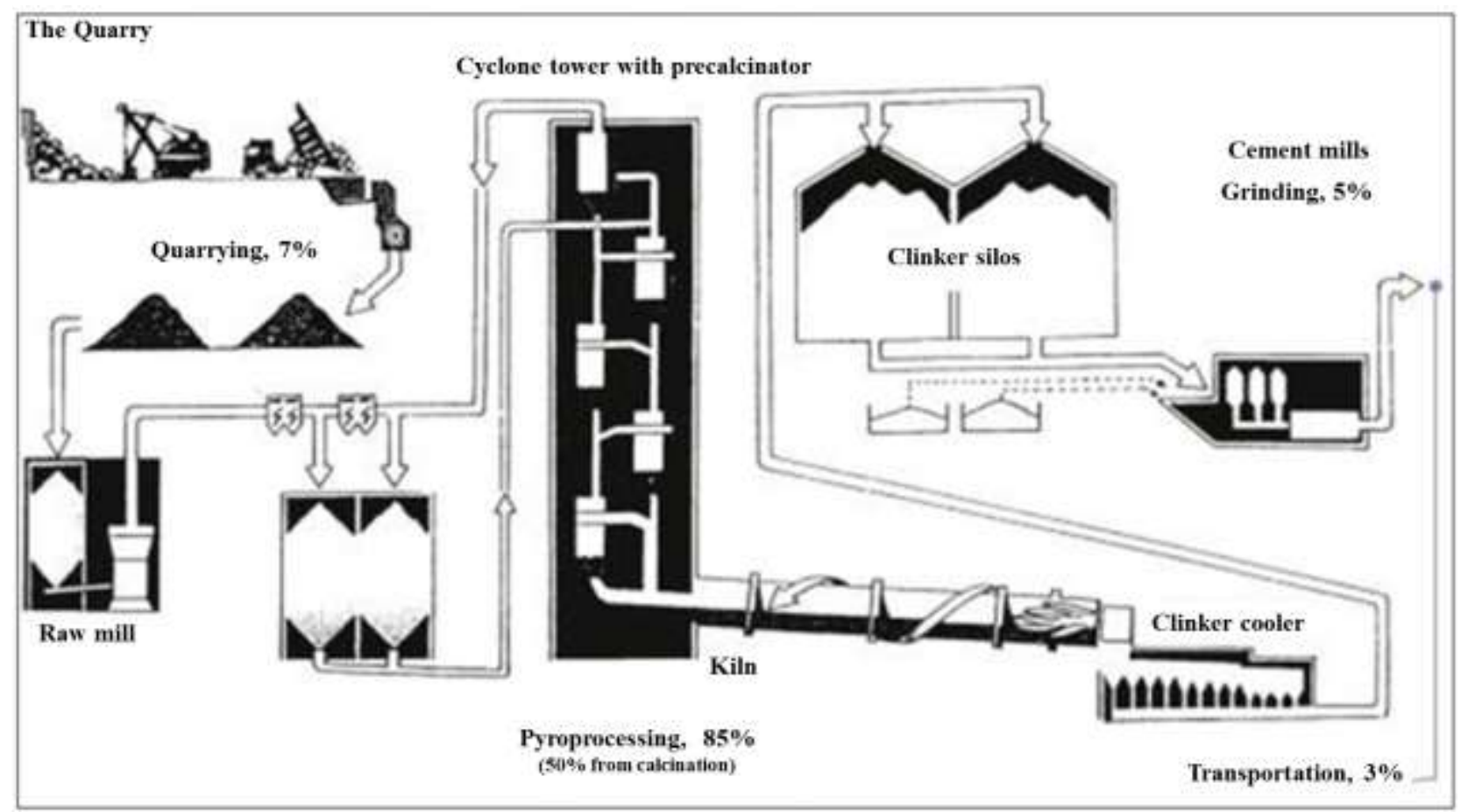

Fig. 1 - $\mathrm{CO}_{2}$ emission process in cement manufacturing

Southeast Asia is among the world's largest sugarcane plantation industry in the world with Thailand, Malaysia, Philippines and Indonesia dominating the list of the top 10 with a total of 165.7 million tonnes per year. Sugarcane bagasse has surged to be amongst the major contributors of Malaysia's solid waste production behind palm oil, municipal and timber waste [8]. It's estimated around 1 ton of sugarcane produces $280 \mathrm{~kg}$ of bagasse after sugar extraction, equivalent to $30 \%$ of waste disposed [8]. Pozzolan is one of the additives that can partially replace cement in soil stabilization. Pozzolan material could be produced by combustion of agricultural waste. Pozzolan inclusions such as SCBA in soil cement mixtures can accelerate the curing hydration when pozzolan reacts with calcium hydroxide and water to form secondary calcium hydrate (CSH) along with calcium alumina silica hydrate (CASH). This process containing additional silica and activated cement alumina thus create an alkaline atmosphere that increases the secondary pozzolanic reaction in the treated soil [7]. Previous study indicates that with $20 \%$ of cement replacement with SCBA have unconfined compressive strength (UCS) reaching $387 \mathrm{kPa}$. It was found this UCS value to be about 30 times better than unstable peat. This proves that the addition of sugar cane ash has a potential to produce a better product in terms of strength [7].

Mass stabilization is a modern ground-stabilization method for a soft soil. Soil stabilization is carried out by mixing a number of dry or wet binder material within the soft soil layer. This soil stabilization method is important as it has been shown to improve the peat structure characteristics and enhance the shear strength. It is a rapid method of improvement, and can be adapted to different soil condition and is economically efficient compared to removal and replacement method which require transportation and soil disposal area. Mass stabilization method in peat soil is adopted to overcome differential settlement. This is because this method is used when the material is very wet (peat, mud or soft clay) [9]. Fig. 2 shows the mass stabilization process on peat. 


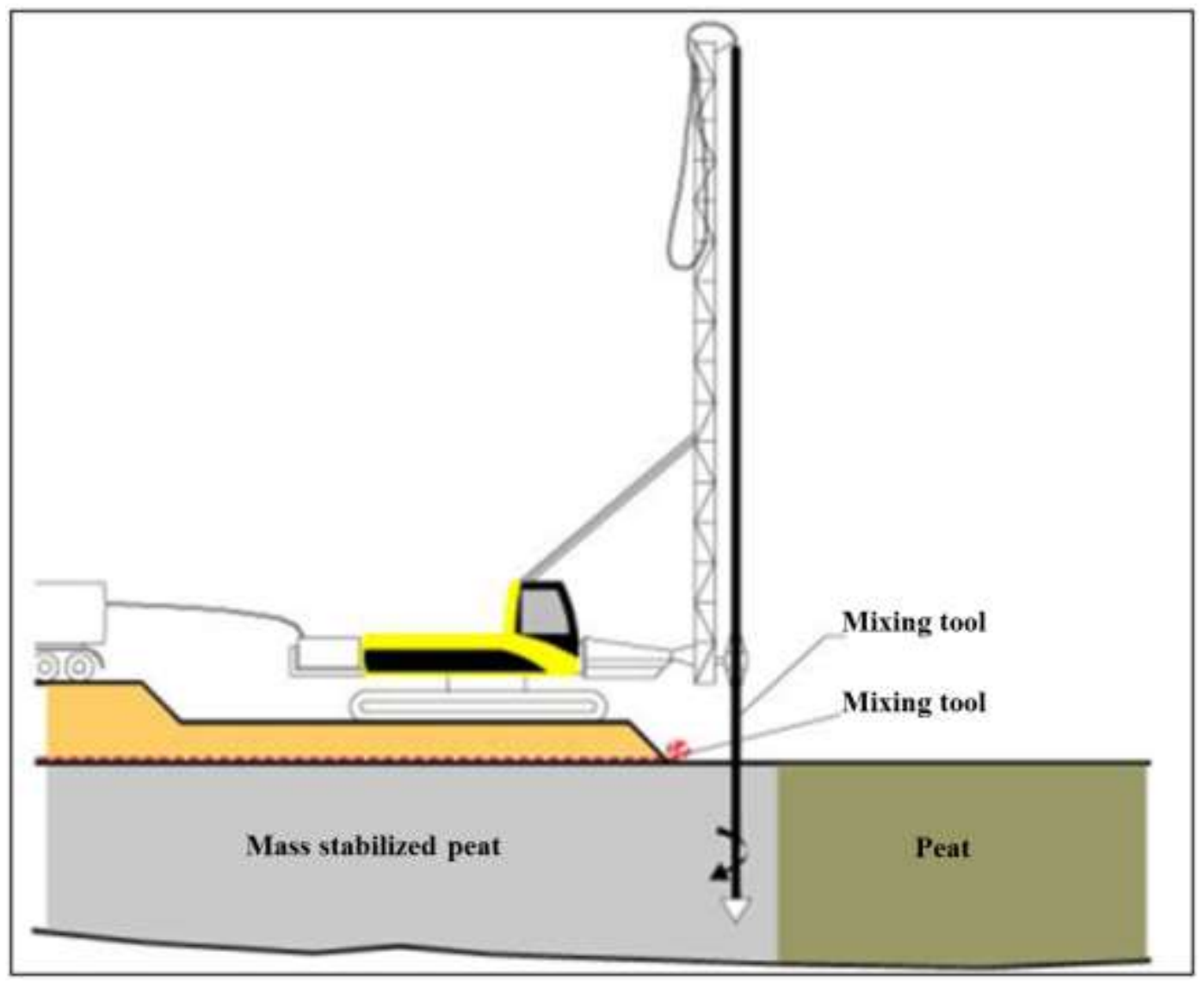

Fig. 2 - Mass stabilization process on peat

\section{Materials and Methods}

Referring to Fig. 3, peat soil samples used in this study were taken from the Research on Peat Station (REPEATS) at Parit Nipah, Batu Pahat, Johor. The disturbed samples were taken at 1 meter from the ground surface. The bagasse was grinded and burned using a furnace. The furnace temperature and the combustion duration were at $500{ }^{\circ} \mathrm{C}$ and 5 hours, respectively. The purpose of the combustion is to remove the moisture. The sample then was sieved using a $63 \mu \mathrm{m}$ sieve to produce fine SCBA. The ordinary Portland cement (OPC) and SCBA were mixed at different mixing ratios as shown in Table 1 . The binder dosage that adopted to stabilize peat in this study is $300 \mathrm{~kg} / \mathrm{m}^{3}$. The tests were divided into two parts namely index properties and mechanical testing as shown in Table 2.

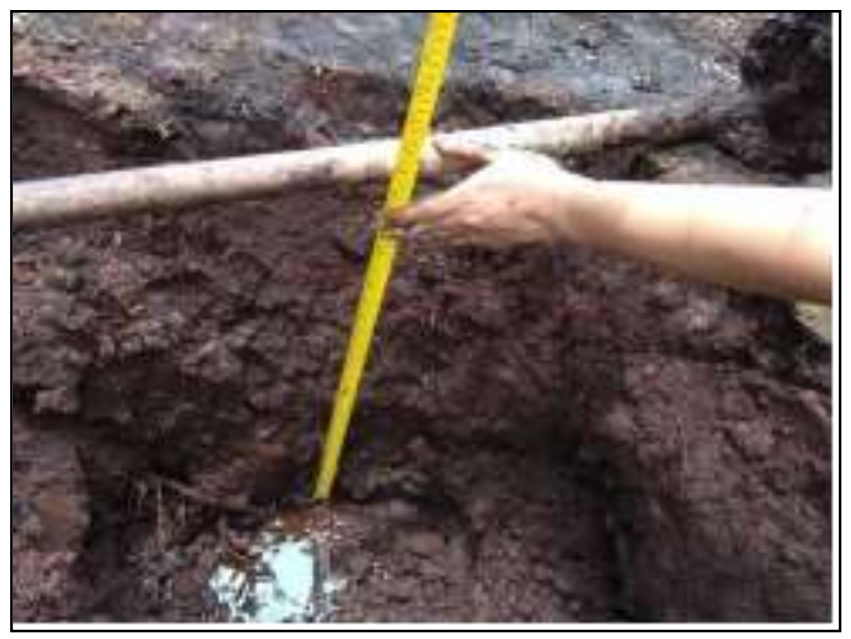

Fig. 3 - Soil sampling at Parit Nipah 
Table 1 - Laboratory mix design

\begin{tabular}{cc}
\hline Material mix ratio & Symbol \\
\hline $100 \%$ cement & C100 \\
$95 \%$ cement $: 5 \%$ SCBA & C95 SCBA5 \\
$90 \%$ cement $: 10 \%$ SCBA & C90 SCBA10 \\
$85 \%$ cement $: 15 \%$ SCBA & C85 SCBA15 \\
$80 \%$ cement $: 20 \%$ SCBA & C80 SCBA20 \\
\hline
\end{tabular}

Table 2 - Index properties test

\begin{tabular}{lll}
\hline Testing & Symbol & Standard \\
\hline Moisture Content & MC & ASTM-D 2974 \\
Organic Content & OC & ASTM-D 2974 \\
pH Value & pH & ASTM-D 4972 \\
Liquid Limit & LL & BS1377 PART 2: 1990:4.3 \\
Specific Gravity & G $_{\text {s }}$ & BS1377 PART 2: 1990:8.3 \\
Particle Size Analysis & PSA & ASTM D422 \\
\hline
\end{tabular}

For mechanical testing, Unconfined Compressive Strength (UCS) was used to determine the treated and untreated samples strength by referring to the ASTM D-2166 standard. A 50mm diameter cylindrical mould specimen and $100 \mathrm{~mm}$ height tested in compression. The samples were cured for 7 and 28 days. The microstructure of the samples was investigated by using Scanning Electron Microscopic (SEM) using JSM 6380LA model to understand the strength gain mechanisms. The samples used in this study were in non-liquid and dry conditions.

\section{Results and Discussions}

Table 3 shows the average of 3 samples results of index properties of the studied peat. The moisture content test was significantly high around $741 \%$. The average value of organic content and ash content were $89.72 \%$ and $10.28 \%$ respectively. According to ASTM D2974, this sample is classified as a peat. The peat sample was highly acidic and low specific gravity at 3.35 and 1.55 , respectively. With $57.5 \%$ of fibrous content and H6 of Von Post test, the peat samples is regarded as hemic peat. The average value of liquid limit test was $300 \%$.

The particle size analysis on SCBA sample shows a finer percentage distribution reaching about $60 \%$ of $45 \mu \mathrm{m}$ in size. In general, pozzolan can act as a filler or secondary pozzolanic reaction. According to ASTM C618, one of crucial requirement of good pozzolan is to obtain at least $66 \%$ of pozzolan finer than $45 \mu \mathrm{m}$. Therefore the SCBA produced can be categorized as low quality.

Table 3 - Index properties result

\begin{tabular}{ll}
\hline Test & Result \\
\hline Moisture content, \% & 741.33 \\
Ash content, \% & 10.28 \\
Organic content, \% & 89.72 \\
pH value & 3.35 \\
Specific gravity, Gs & 1.55 \\
Fibrous content, \% & 57.5 \\
Liquid limit (LL), \% & 300 \\
\hline
\end{tabular}

The UCS results for all samples were shown in Fig. 4 and Fig. 5. The UCS of untreated peat was $16 \mathrm{kN} / \mathrm{m}^{2}$. It was observed that the maximum UCS of the treated samples after 7,14 and 28 days curing were $185 \mathrm{kN} / \mathrm{m}^{2}, 233 \mathrm{kN} / \mathrm{m}^{2}$ and $278 \mathrm{kN} / \mathrm{m}^{2}$ respectively. All these maximum values occurred at 5\% replacement of SCBA. Furthermore, these results indicates that the samples of 28 days curing show the highest values and about 17 times greater than untreated peat. However, compared to the maximum UCS of C100 $\left(206 \mathrm{kN} / \mathrm{m}^{2}\right)$, the UCS increment of 28 days curing sample was approximately only $35 \%$ and seems rapidly decrease after 5\% of SCBA replacement. The possible reason of this outcomes due to quality of the SCBA that had been used which act only as a filler at early stage of strength gain in this study. However, 5\% of cement replacement (C95SCBA5) was suggested since its still shows better improvement compared to without SCBA replacement (C100).

Electron scanning Microscope (SEM) tests have been carried out on samples before and after stabilization as shown in Fig. 6 to Fig. 8. Based on Fig. 6, SEM for untreated sample is seen to have many hollow conditions due to loose fibre with high water content in peat samples. Referring to Fig.7, the microstructure of C100 sample was 
observed to be more compacted which indicates the reduction of voids compared to untreated sample. While for Fig. 8, the optimum mixture (C95SCBA5) shows the best microstructure condition amongst the other mixture as a result of SCBA inclusion within the pore spaces.

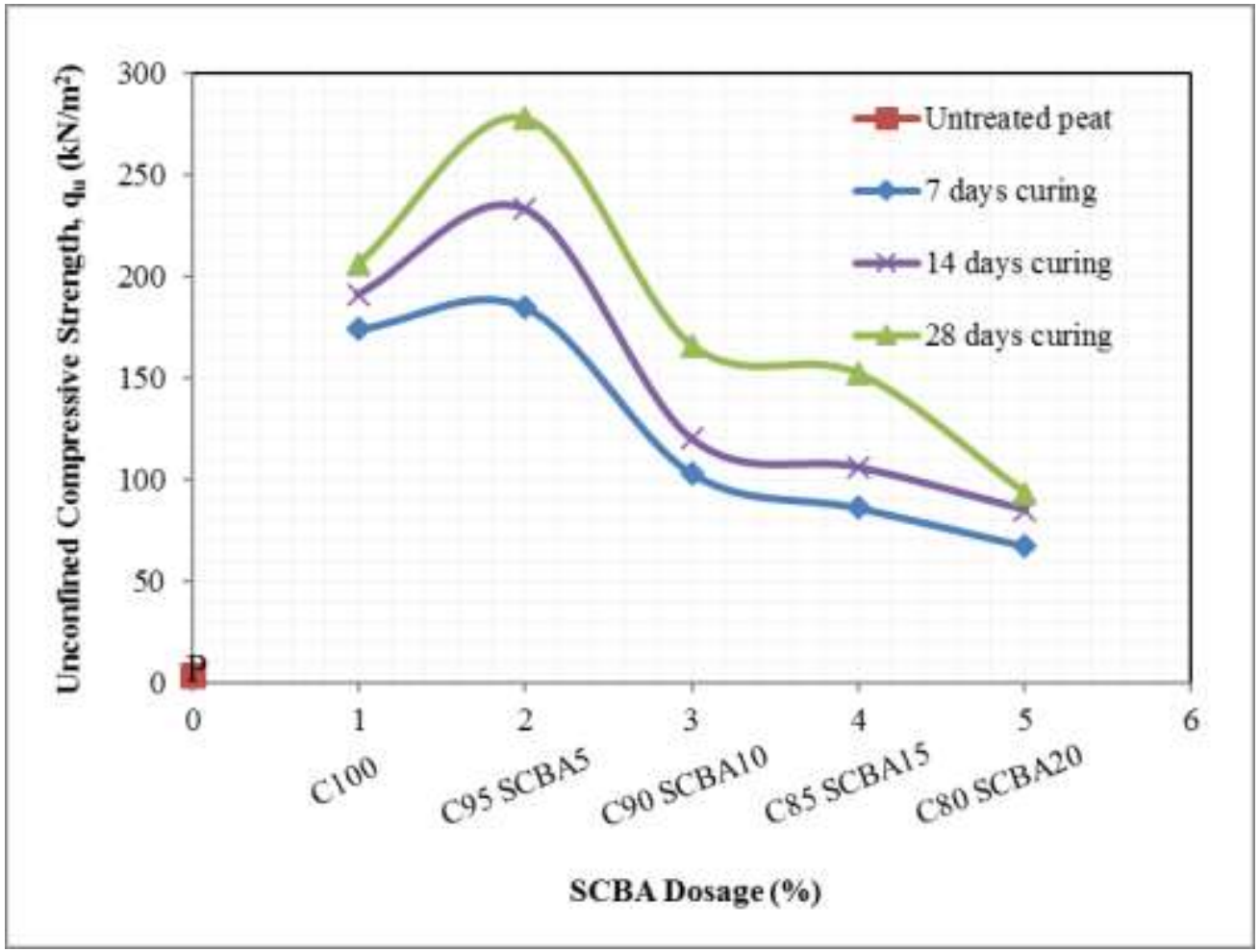

Fig. 4 - UCS vs mix ratio

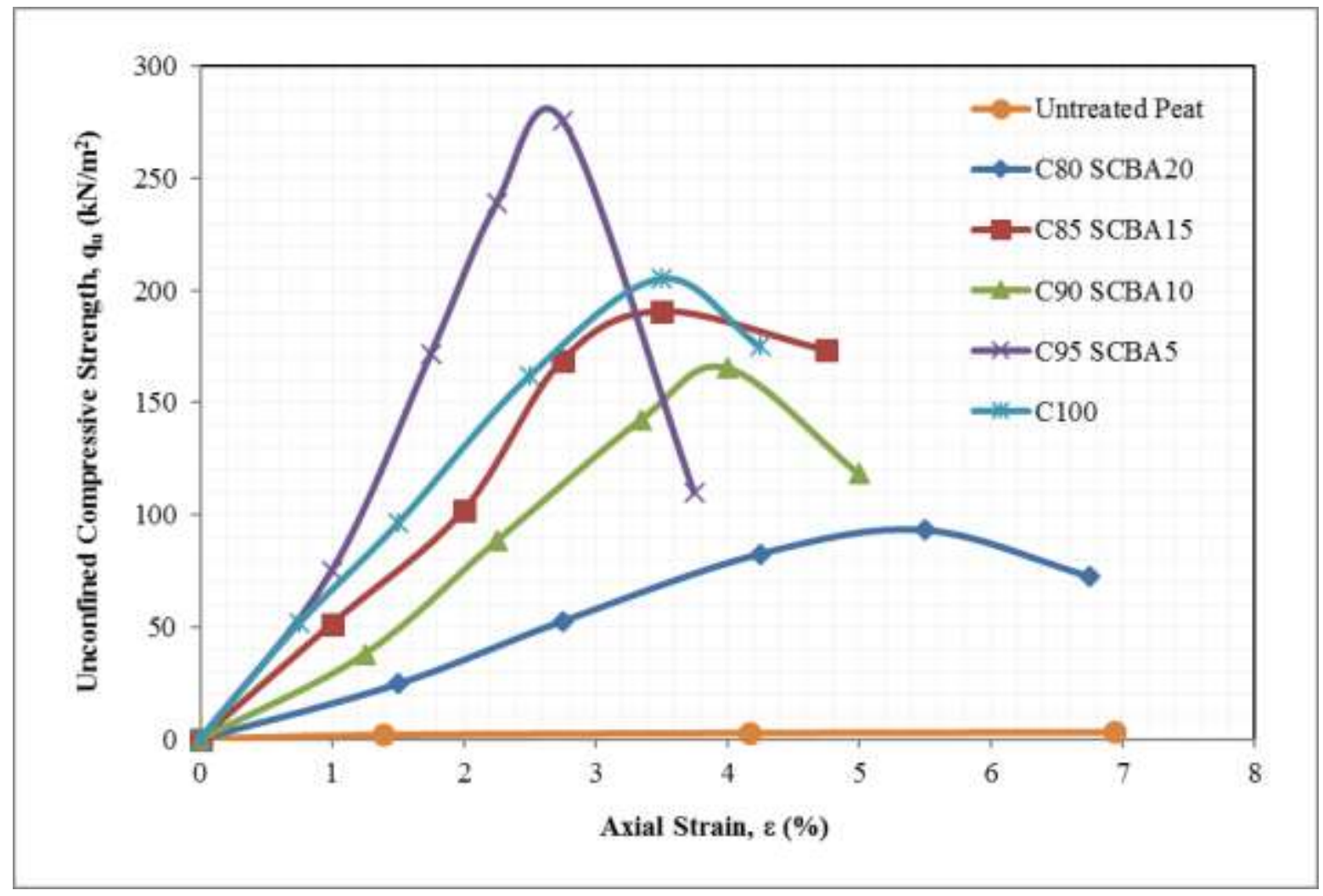

Fig. 5 - UCS Test for 28 days curing 


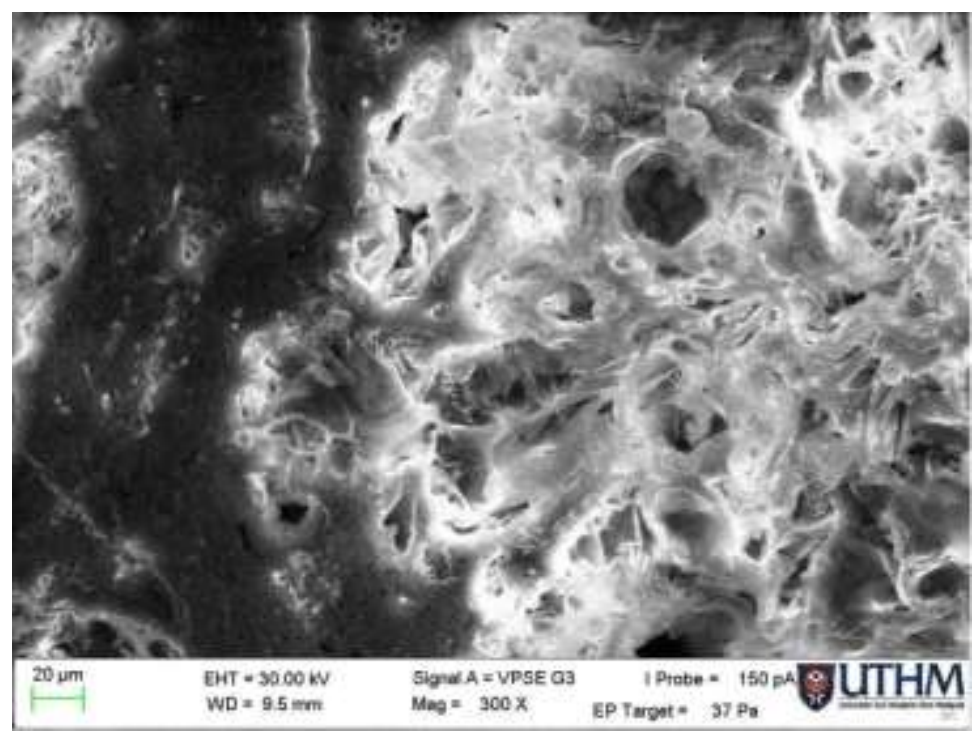

Fig. 6 - Microstructure image for untreated peat soil

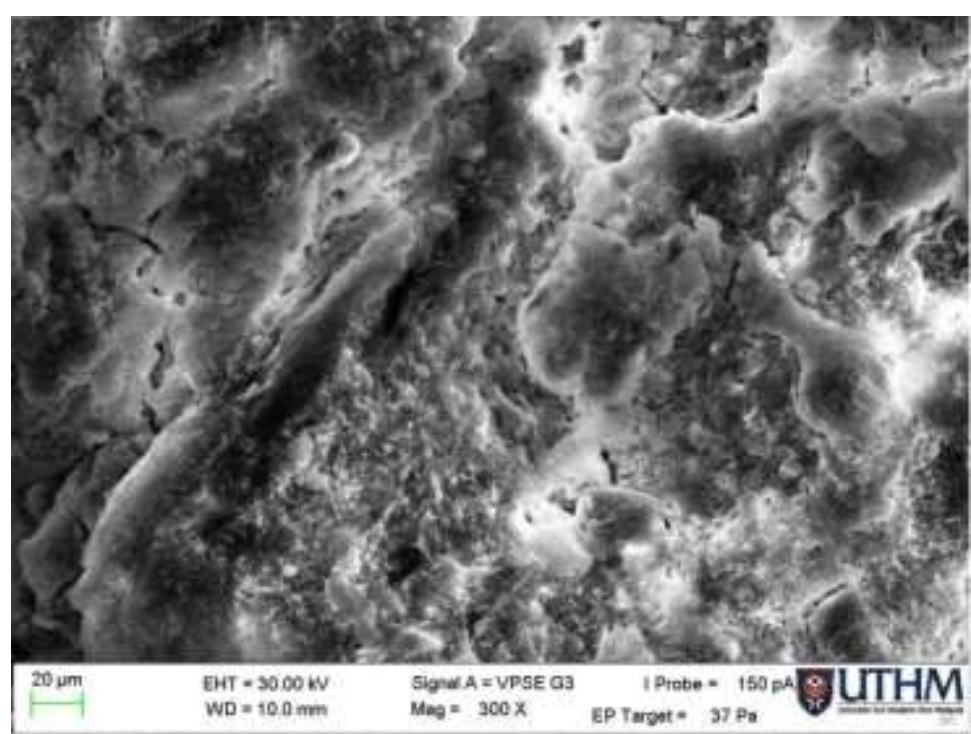

Fig. 7 - Microstructure image for sample C100

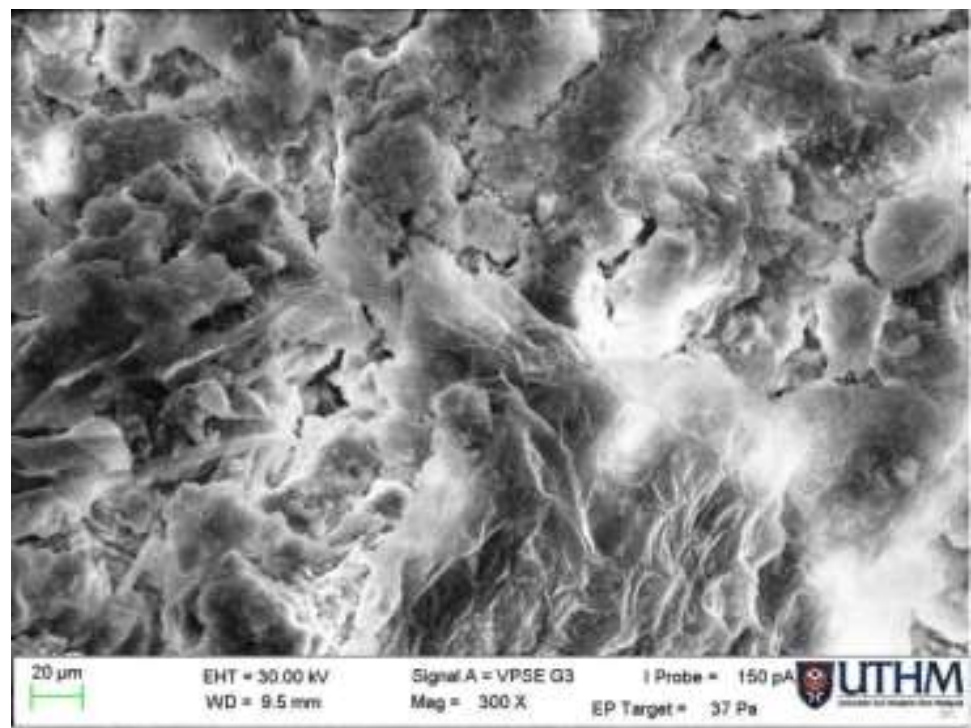

Fig. 8 - Microstructure image for sample C95SCBA5 


\section{Conclusions}

The results of this study show the peat soil strength has proven to be greatly improved after stabilized with cement and SCBA mix ratio. It can be concluded that 5\% partially replacement of cement by using SCBA shows the best mixture due to filler effect on the treated peat. This is supported by the maximum UCS of 7,14 and 28 curing days at $5 \%$ SCBA replacement which were $185 \mathrm{kN} / \mathrm{m}^{2}, 233 \mathrm{kN} / \mathrm{m}^{2}$ and $278 \mathrm{kN} / \mathrm{m}^{2}$ respectively. The maximum UCS value was found about $35 \%$ greater than $\mathrm{C} 100$ mixture (100\% cement) and 17 times better than untreated peat. The SEM test shows the microstructure of treated sample was visually observed to be more compacted which indicates the reduction of voids compared to untreated sample.

\section{Acknowledgement}

This research was supported by Ministry of Higher Education (MoHE) Malaysia and Research Management Centre, RMC, UTHM through Fundamental Research Grant Scheme (FRGS/1/2019/TK08/UTHM/03/1) and Geran Penyelidikan Pascasiswazah, GPPS (H636). Special gratitude to all the staff members of Faculty of Civil Engineering and Built Environment (FKAAB), Research Centre for Soft Soil (RECESS) Universiti Tun Hussein Onn Malaysia (UTHM) for the valuable support.

\section{References}

[1] Huat B.K, Arun Prasad, Afshin Asadi, S. K. (2014). Geotechnisc Of Organisc Soil and Peat. CRC Press / Balkema.

[2] Munro, R. (2004). Dealing With Bearing Capacity Problems on Low Volume Roads Constructed on Peat, 136

[3] Paramananthan, S. (2010). Keys to the identification of Malaysian soils according to parent materials (Mimeo). Param Agricultural Soil Surveys, Selangor., 2(1)

[4] Hebib, S., \& Farrell, E. R. (2003). Some experiences on the stabilization of Irish peats. Canadian Geotechnical Journal, 40(1), 107-120. https://doi.org/10.1139/t02-091

[5] Janz M, J. S. (2002). The function of different binding agents in deep stabilization. Swedish Deep Stabilization Research Center, Linkoping

[6] Rubenstein, M. (2012). Emissions from the Cement Industry. Swedish Deep Stabilization Research Center, Linkoping., 4(3)

[7] Abu Talib, M.K., \& Noriyuki, Y. (2017). Highly Organic Soil Stabilization by Using Sugarcane Bagasse Ash ( SCBA ). International Symposium on Civil and Environmental Engineering 2016, 7013, 1-8.

[8] Parameswaran Binod. (2009). Sugarcane Bagasse. In: Singh nee' Nigam P., Pandey A. (eds) Biotechnology for Agro-Industrial Residues Utilisation, 1(3)

[9] Allu. (2012). Allu Stabilisation System -Mass Stabilisation 